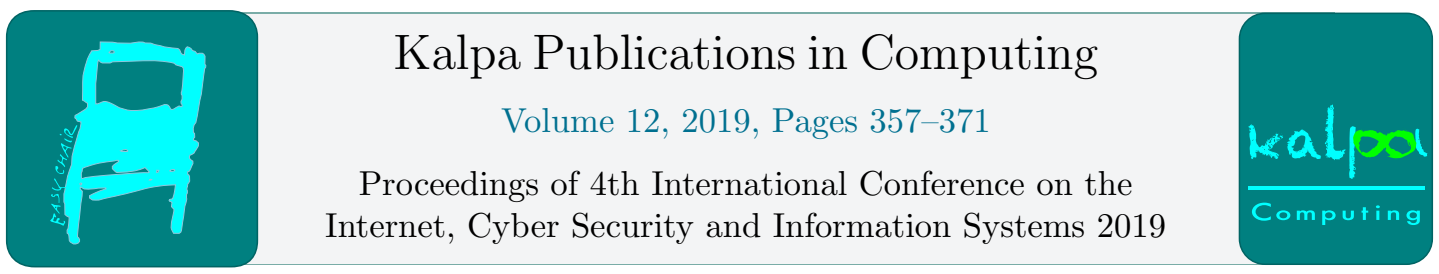

\title{
Impacts and Satisfaction of Using Smartphones for Learning in a University Context
}

\author{
B-Abee Toperesu ${ }^{1}$, Jean-Paul van Belle ${ }^{1}$ and Marita Turpin ${ }^{2}$ \\ ${ }^{1}$ University of Cape Town, Cape Town, South Africa \\ ${ }^{2}$ Department of Informatics, University of Pretoria, Pretoria, South Africa \\ batops@gmail.com, Jean-Paul.VanBelle@uct.ac.za, \\ Marita.Turpin@up.ac.za
}

\begin{abstract}
The use of smartphones for learning has increased dramatically due to the availability of affordable data and free WiFi networks across universities. However, the impact that smartphones have on a student's overall learning experience needs more investigation. This paper looks at the positive and negative impacts smartphone use has on a student's learning experience and whether this leads to an overall satisfaction with mobile learning. Quantitative data was collected through an online survey that was distributed via e-mail to a student body at one South African university. With over 400 responses, we found evidence for some, but not all hypothesized positive and negative impacts. Additionally, there was strong support for how these impacts contribute to overall satisfaction of using a smartphone for learning, explaining more than $60 \%$ of the variance. We also found that the overall positive satisfaction leads to differentiated, continued uses of the smartphone.
\end{abstract}

Keywords: Smartphone, Mobile Learning, Impact, Satisfaction, South African Higher Education.

\section{Introduction}

The phenomenon of mobile learning (mLearning) has been widely researched in the scholar community. The need to offer improved pedagogical approaches to enhance learning is seen as one of the biggest drivers of for the increase in this research field (Ally, Grimus, \& Ebner, 2014). Distance learning and higher education institutions are particularly prominent in pioneering and embracing mobile learning (Brown \& Mbati, 2015). To the student, mobile learning means the ability to learn from anywhere, it means being more productive and saving time (Moreira, Pereira, Durão, \& Ferreira, 2018). To the institutions it may reduce demand for institutional resources such as desktop PCs and library books and it may also result in higher enrolment figures and more graduates (Wai, Ng, Chiu, Ho, \& Lo, 2018). 
However, many challenges are hindering the adoption of mobile learning in the African context, such as limited mobile data coverage and the affordability of data. Institutional challenges are also inherent where the bandwidth on campus is inadequate, the learning material is not mobile friendly, and security policies are inadequate to cater for diverse mobile devices connecting to their network (Ossiannilsson, 2016). Because of these issues and hindrances, the impact mobile devices have on the overall learning experience in higher education has not been clearly determined in recent studies.

Previous studies that investigated the field of mobile learning generally looked at all mobile devices that included tablet computers and laptop computers (Kaliisa \& Picard, 2017). In a South African context, the need to focus on smartphones is probably more important because of the high rate of ownership among students in higher education. Recent research found that more than $90 \%$ of students in higher education own a smartphone (Kaliisa \& Picard, 2017; Lau, Chiu, Ho, Lo, \& See-To, 2017). In developing countries such as South Africa this could be a starting point for enabling mobile learning as low device ownership had greatly hindered mobile learning diffusion in the past. The South African context of this research is of particular importance because various mobile learning adoption factors are dependent on the economic and social context of the students. Economic settings such as affordability of devices, mobile data costs, and government policies do play a major role in influencing the behaviour of the students with regard to smartphone learning.

The paper's main research question is to investigate the impacts of, and satisfaction with smartphone use for learning in a South African university context. The sub-questions are:

- How do South African university students use their smartphones for learning (i.e. use cases)?

- What are the positive and the negative impacts of smartphone use?

- What are the main perceived barriers towards using smartphones for learning?

- How do the impacts and barriers impact on the overall satisfaction with using a smartphone for learning purposes?

\section{Related Work}

There has been a growing emphasis on using information and communication technologies (ICTs) for development in South Africa and other developing countries. ICTs have been considered as crucial for development in society (Magunje, 2013). Mobile technology plays a contributory role as part of the development. People in developed countries are swiftly moving from desktop computers to mobile devices. However, this is not the case in developing countries. Ally (2013) notes that people in developing countries are going directly to acquiring mobile devices instead of first owning desktop computers. This is because of the attractive and affordable prices of mobile devices (Hashemi, Azizinezhad, Najafi, \& Nesari, 2011).

\subsection{E-Learning vs M-Learning}

Electronic learning, popularly known as e-learning, is the use of computers or electronic devices to facilitate learning. Various definitions exist which attempt to define this phenomenon. Guri-Rosenblit (2005) defines e-learning as, "the use of electronic media for a variety of learning purposes that range from add-on functions in conventional classrooms to full substitution for the face-to- face meetings by online encounters" (p.469). Another definition states that e-learning is, "information and communication technologies used to support students improve their learning” (Ellis, Ginns, \& Piggott, 2009). In both definitions it can be noted that e-learning makes use of technologies, which per the above definitions should include mobile devices. However, when mobile devices are used for learning 
purposes the process is referred to as m-learning. The question then arises as to what differentiates the two.

Although e-learning and m-learning make use of information and communication technologies that connect to the internet, they differ in the ways they are utilized. The main distinction is that e-learning tends to make use of desktop computers or immovable devices while m-learning makes use of mobile devices such as laptops, mobile phones and tablet computers. Mobile devices have characteristics that set them apart from other e-learning devices, such as mobility and usually smaller screens. These characteristics may lead to m-learning occurring differently than e-learning.

\subsection{Mobile Learning in Higher Education Institutions}

Mobile devices have continued to advance in terms of hardware and software improvements. These devices have processing power similar to desktop computers and in some cases even supersede them. At the same time, mobile networks have been continually advancing in terms of connectivity and network speed. Mobile learning in education has therefore become an attractive and a suitable option (Abachi \& Muhammad, 2014).

Several studies have been done on mobile learning in higher education institutions. A meta-analysis literature review examining 163 mobile learning studies done between 2003 and 2010 found out that mobile learning is commonly practiced in high education institutions (Wu et al., 2012). This is because of the widespread ownership of mobile devices and the increased availability of wireless connections at higher education institutions (Hashemi et al., 2011). Recent research studies reveal that up to $96 \%$ of students in high education institutions own a mobile device and, in some cases, bring more than one mobile device to campus, while in future mobile device ownership will be further increasing (Dahlstrom \& Bichsel, 2014; Kobus, Rietveld, \& Van Ommeren, 2013; Santos, 2015).

In most cases, the use of mobile devices for learning purposes in higher education institutions is aligned to their goals and mission or vision (Hashemi et al., 2011). Such goals include examples like the inclusion of different learning methods and reaching out to learners across geographic locations.

The use of mobile devices in higher education institutions is viewed as a relevant development to higher education learning. To the learner the benefits include the ability to access blended learning course material from anywhere and at any time and the ability to collaborate with peers (Kobus et al., 2013).To the institution the main benefit is the relief of strain on the use of institutional computers as learner bring their own devices.

\subsection{Mobile Learning Characteristics}

Mobile learning has seven basic characteristics i.e. ubiquitous, portable, blended, private, interactive, collaborative, and instant information (Ozdamli \& Cavus, 2011). Ubiquitous refers to mobile learning as being available everywhere and on multiple platforms. Portable means that mobile devices are small enough to be carried around. Blended mobile learning combines the benefits of online instruction and traditional face-to-face teaching. Mobile learning is also characterized as private since the device is personal. Interactive means that students are not passive but can participate in the learning process. Collaboration means that communication with lecturers as well as other students is supported. Instant information refers to immediate access to learning material (Ozdamli \& Cavus, 2011).

\subsection{Learning Theories}

Various theories exist which show how people learn and develop knowledge. These theories help in understanding the various ways people learn. The most common theories are grouped into three categories namely behaviourism, cognitivism, and constructivism (Siemens, 2005). 
Behaviourism proposes that the learner is passive and sensitive to the environment. The learner's behaviour is then shaped by the negative or positive changes in the environment (David, 2007). Cognitivism came forth in the 1960s and replaced behaviourism as the main model for learning. Cognitivism states that knowledge is a result of mental constructions. It states that the mental processes which include memory and thinking need to be looked at in detail as these inner mental activities help to understand how people learn (Sincero, 2011). The third theory class namely constructivism states that knowledge is constructed. It claims that learning is a process of constructing knowledge instead of gaining it as the learner takes past experiences and other factors such as culture into account (David, 2015).

Siemens (2005) argues that the problem with these theories is that they were development in a pretechnological era and thus fail to take any contribution from technology into account. He advances a theory called connectivism, that takes into account the use of technology. It takes into account various theory constructs and combines them with social structures and technology to come up with a theory for the digital age. Connectivism states that, "Learning is a process that occurs within nebulous environments of shifting core elements - not entirely under the control of the individual" (Siemens, 2005), p. 5. The theory further claims that learning, which can reside externally, is focused on connecting separate information sets that enable us to learn more. Therefore when new tools are used, this will change how individuals work or function. Since smartphones (being a personalized device) is an extension of the self (more so than a computer that may be shared), it may facilitate learning that resides externally. We therefore we believe that the theory of connectivism is relevant to mobile learning.

\subsection{Benefits of Mobile Learning}

Mobile learning presents a host of benefits to the learner. One of the main benefits is the affordability that comes with mobile devices (Vishwakarma, 2015). The prices of mobile devices compared to more robust technology such as desktop computers is much less. In developing countries like South Africa, the uptake of mobile phones far outweighs that of desktop PCs.

Affordability of the mobile devices becomes a benefit to the learning institutions as they are able to offer learning materials to more students. To accommodate more students, the institutions will only need to expand their network capabilities and increase educators who facilitate the online content (Yusuf, Lawal, \& Oyewusi, 2015). There will not be a need for more classroom facilities as an alternative to face to face interactions is offered through mobile devices. Thus education becomes more scalable (Ally, 2013).

Learning material offered online is easy to update (Yusuf et al., 2015). Mobile devices are able to update the material as soon as it is made available ensuring that learners use the latest available material. Mobile device features are fast advancing making the devices capable of performing many more functions quicker and more efficiently (Alrasheedi \& Capretz, 2013).

Other benefits of mobile learning include convenience, accessibility, portability, efficiency and flexibility (Briz-Ponce, Pereira, Carvalho, Juanes-Méndez, \& García-Peñalvo, 2017).

\subsection{Challenges Related to Mobile Learning}

One of the challenges with mobile learning is people's perceptions and attitudes with using mobile technologies for education. Some educators feel that mobile devices cause too much distraction for learners, and/or associate mobile device use during lectures with bad behaviour (Ally, 2013).

Information security and privacy has remained a top priority among IT leaders globally as cybercriminals are on the increase and higher education institutions are no exception. Cybercrime can be described as any criminal activity where a computer or computer network is either a tool, place of 
crime, source of crime or is a target (Pozár, 2014). According to a leading security firm Symantec, the education sector is now the third most frequently breached public sector (Haley, 2015).

Different forms of threats exist, targeting institutional data, the network or personal data residing on an individual's devices. Some examples of information security threats include, malware \& virus infections, cyber fraud and hacking. As mobile devices become prevalent in universities, more and more mobile devices become susceptible to these threats. Smartphone hacking software is also now easily available online. This software is used to steal passwords and any personal information.

Another information security factor is that mobile devices can be lost or stolen. Once these mobile devices land in the hands of criminals, if not secured, it can lead to harm done to the institution or its network. Although this can be countered by remote wiping of the devices that are stolen or lost, this responsibility lies with the owner as the device personally belongs to them. In most cases educational institutions have no control over personal devices.

Other methods to ensure information security and privacy are available. The most common method is enforcing detection software. Programs that detect and filter infections using algorithms and signature based matching techniques have been developed. These programs identify malware before it reaches the computer system or network (Zolkipli \& Jantan, 2010). Further advancements in enterprise systems security include endpoint security. With endpoint security, each device must meet certain standards before it is granted access to the organization's network. Examples of endpoint security include personal firewalls and antivirus software that is distributed, monitored and updated from the server (Rouse, 2011).

Awareness campaigns can also be undertaken to raise users' awareness of criminal activities. An increase in the number of phishing attempts shows that the target is now the user and cybercriminals seek to exploit their lack of knowledge. While organizations are increasingly advancing their security technologies, very little is invested in increasing safety awareness among general users, consequently causing them to be the weakest link on the organization's system (Aloul, 2012). Social awareness campaigns can be run to inform people of prevalent security issues.

Based on the dominance and persisting nature of information security and privacy as reflected in previous research studies, information security and privacy will continue to be a pressing issue for the next few years. IT leaders in higher education need to prioritize and focus on their security as more cyber-attacks are now coming to the education sector.

\section{Research Methodology}

The conceptual model depicted in Figure 1 was developed. The model represents the links of the various constructs which include Smartphone Use, Issues, Satisfaction and positive and negative impacts. The researchers propose that there is a link between all four constructs of the model that will be validated through testing of the hypotheses. A set of hypotheses are proposed to show and explain the empirical relationship between the various constructs in the research framework. These hypotheses and the related conceptual model were informed by the work of Bhattacherjee (2001) as well as Wai et al. (2018). The hypotheses will be tried and either confirmed entirely or in part, or completely invalidated, which will prompt the further advancement of theory which at that point might be pursued by further research (Saunders, Lewis, \& Thornhill, 2009).

The following hypotheses will be tested (Figure 1):

- Hypothesis 1: The greater the use of smartphone applications for learning purposes, the more the positive impact.

- Hypothesis 2: The greater the use of smartphone applications the more negative impacts will be experienced. 
- Hypothesis 3: the higher the positive impact, the greater the user satisfaction with using smartphones for learning

- Hypothesis 4: the greater the negative impact the lower the user satisfaction.

- Hypothesis 5: The more issues are experienced, the lower the user satisfaction.

- Hypothesis 6: The greater the user satisfaction with the smartphone as a learning device, the more it will (continue to) be used.

Quantitative data was collected from higher education students through a survey in a cross-sectional timeframe. The sampling technique employed was representative sampling within one higher education institution in South Africa. The research instrument, using a mixture of pre-existing questions (refer to literature review) and new questions which had likert scale answer options. It was distributed online via an e-mail invitation. A total of 499 responses were recorded. 96 responses were excluded as there were incomplete leaving a total of 403 responses to be used for the analysis. Statistica 13 was used for the analysis.

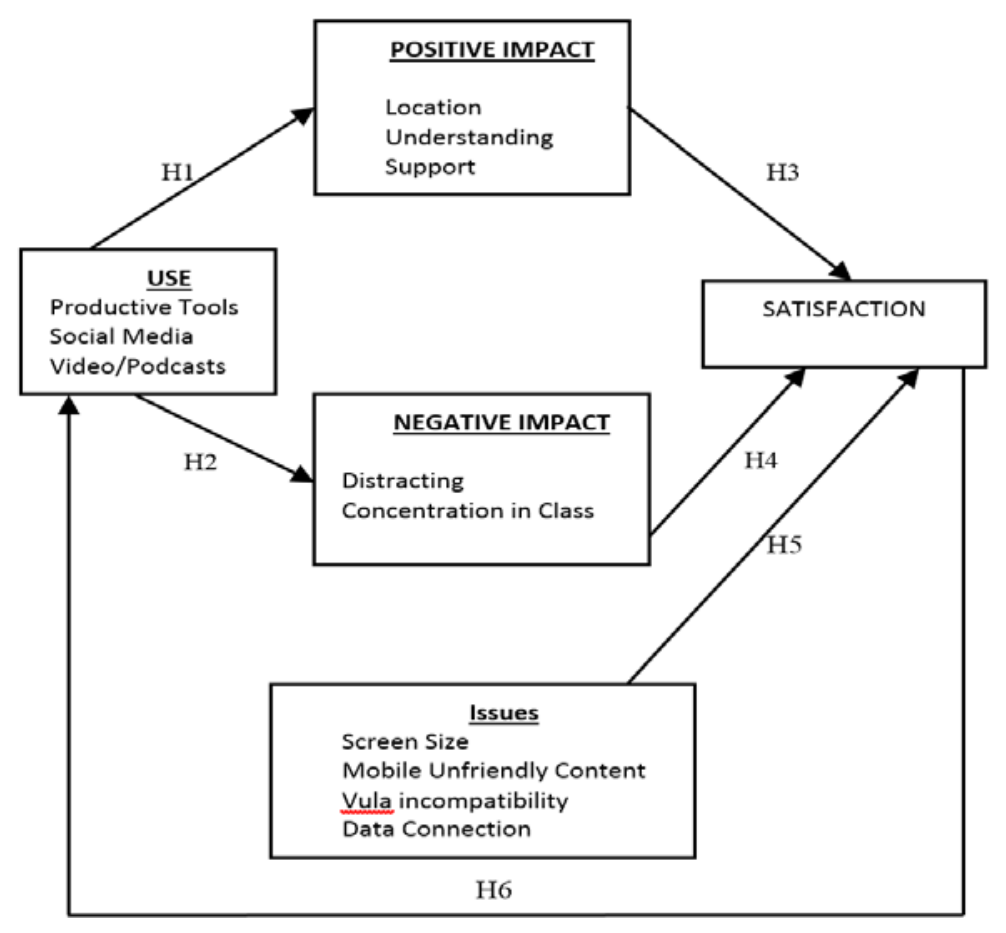

Figure 1: Research model adopted for the research 


\section{Data Analysis and Discussion}

\subsection{Descriptive analysis}

Frequency of use of mobile applications for learning

Students were asked how frequently they made use of some of the mobile applications on their phones in relation to their learning. A 7-point Likert scale was used. The responses were recorded and have been presented in a stacked bar chart below (Figure 2) sorted by weighted averages.

Internet browser topped the list as the mostly used app by students with 135 of the 401 participants recording that they make use of the app for their learning. This affirms the claim that students mostly use the web browsers on their smartphones to quickly access urls with course-related learning material (Al-Emran, Elsherif, \& Shaalan, 2016). Figure 2 further reveals that students rarely use social media apps for learning. Facebook had the majority of students who confirmed that they never use it for learning. Interestingly some students frequently use WhatsApp for learning. This is aligned with previous scholarly findings which reveal that WhatsApp is the most popular messaging app amongst students and that they use it ask questions and collaborate amongst themselves through WhatsApp study groups (García-Peñalvo \& Conde, 2015).

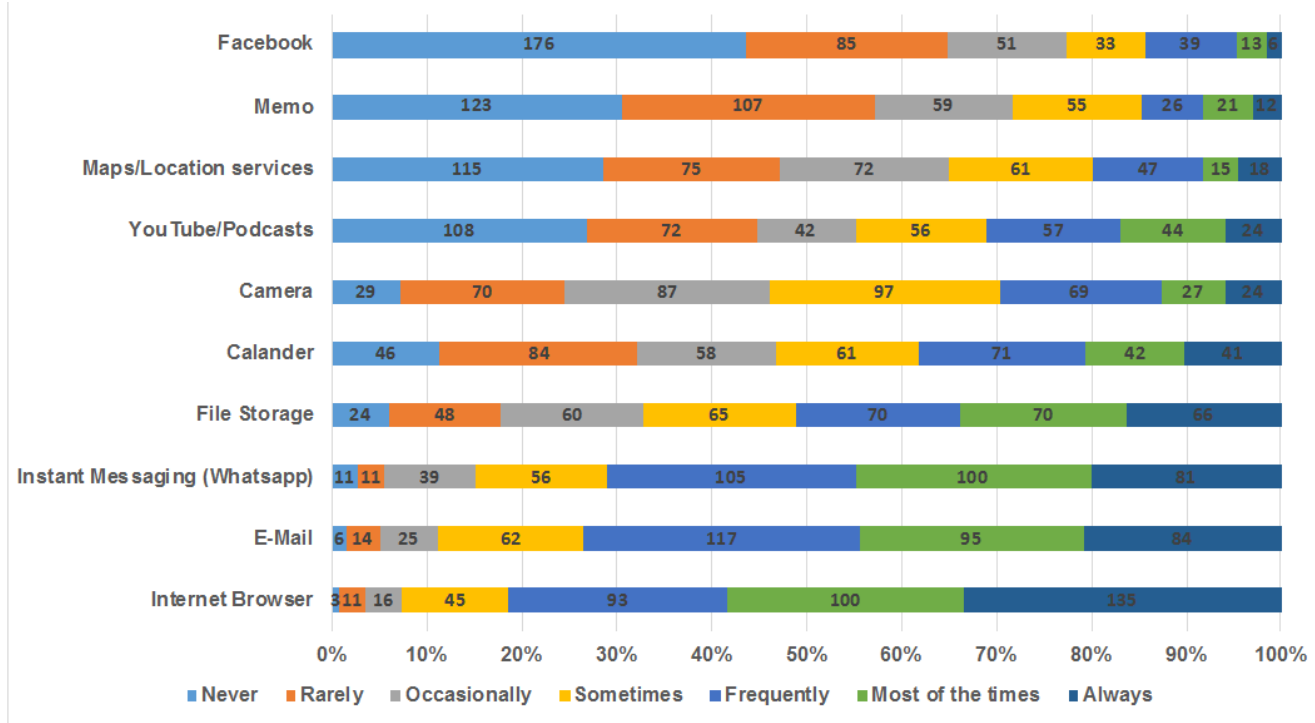

Figure 2: Smartphone functionality according to frequency of use

The popular video app YouTube appears not to have a good uptake by students when it comes to learning as over $25 \%$ of students never use it all. This might be due to the fact that there might not be relevant videos relating to their study content that has been published in video format (Kuznekoff \& Titsworth, 2013). 


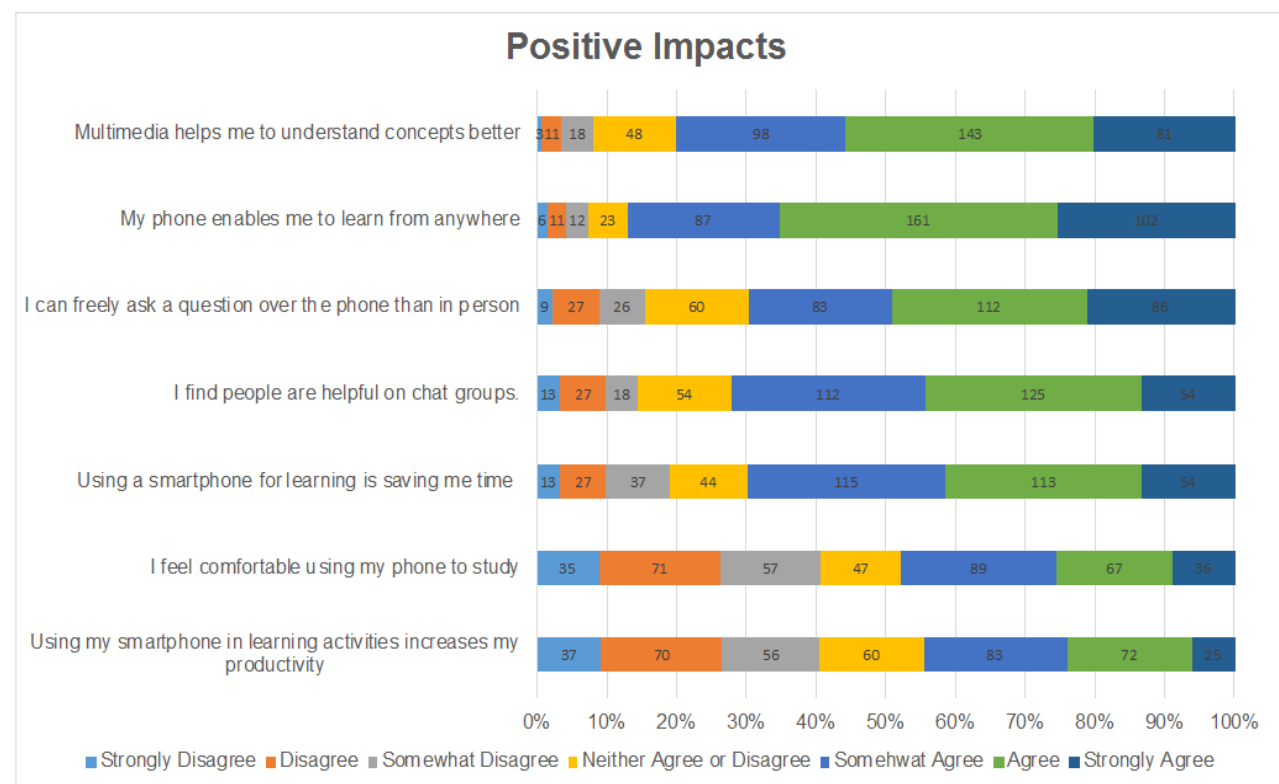

Figure 3: Positive impacts of using a smartphone for learning purposes.

\section{Positive Impacts}

The research questionnaire had a section with a set of questions that sought to understand how smartphones are positively impacting their learning. Figure 3 reveals some of the findings under this section. The largest positive impact seems to be the 'learn from anywhere' impact, although multimedia is also seen as aiding understanding. Connecting with other people and time savings are also rated highly.

\section{Negative Impacts}

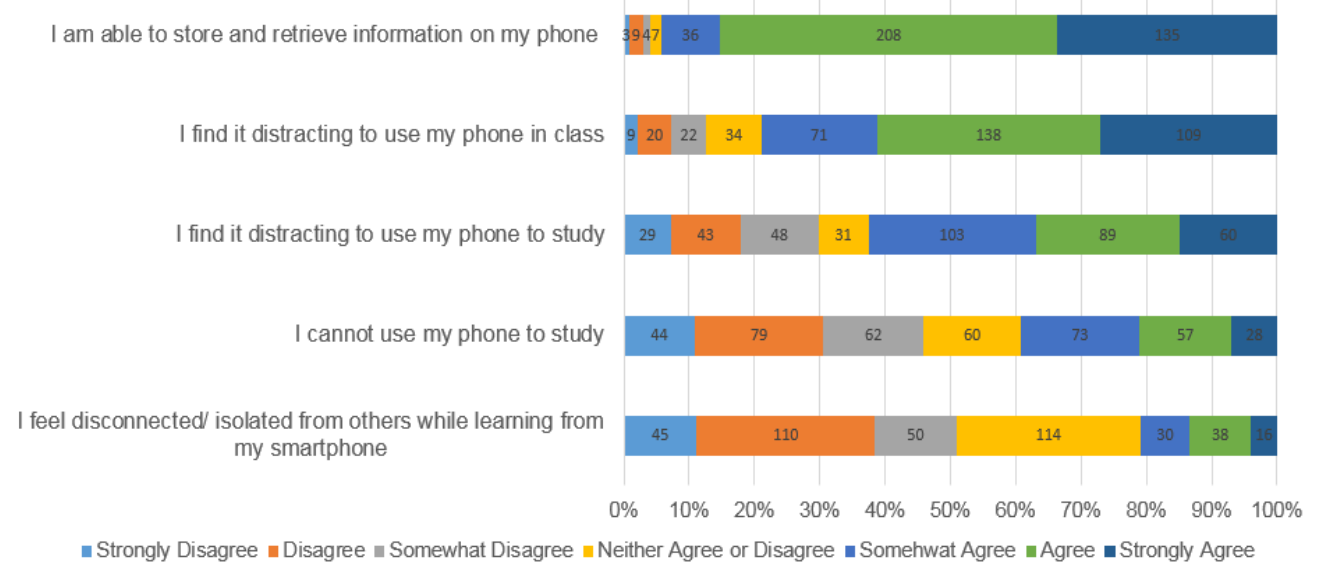

Figure 4: Negative impacts of using a smartphone for learning purposes. 


\section{Negative Impacts}

The research instrument further sought to uncover the negative impacts of learning on smartphones. Some negatives that came out strongly are that students find mobile phones distracting while studying with very few disagreeing (Fig. 4). Previous research also found out that mobile phone use for learning by students could be distracting (Magunje, 2013).

\section{Issues}

The issues that were encountered by students while learning on their smartphones mainly related to mobile data access. Most students strongly agreed that they depend on free WiFi to access learning material from a smartphone. Fortunately, free WiFi on campus is adequate to meet this need as agreed to by 104 students as depicted in the stacked bar chart on figure below. Access to Vula, the learning management system in use at the University, was not seen as an obstacle or issue; presumably this is due to it now having a dedicated mobile phone interface. Another issue that concerned more than half of the students, was that the small screen of a mobile phone makes it difficult to learn. This finding is in line with previous research where it was found that students prefer to learn from computer screens rather than phones (Magunje, 2013).

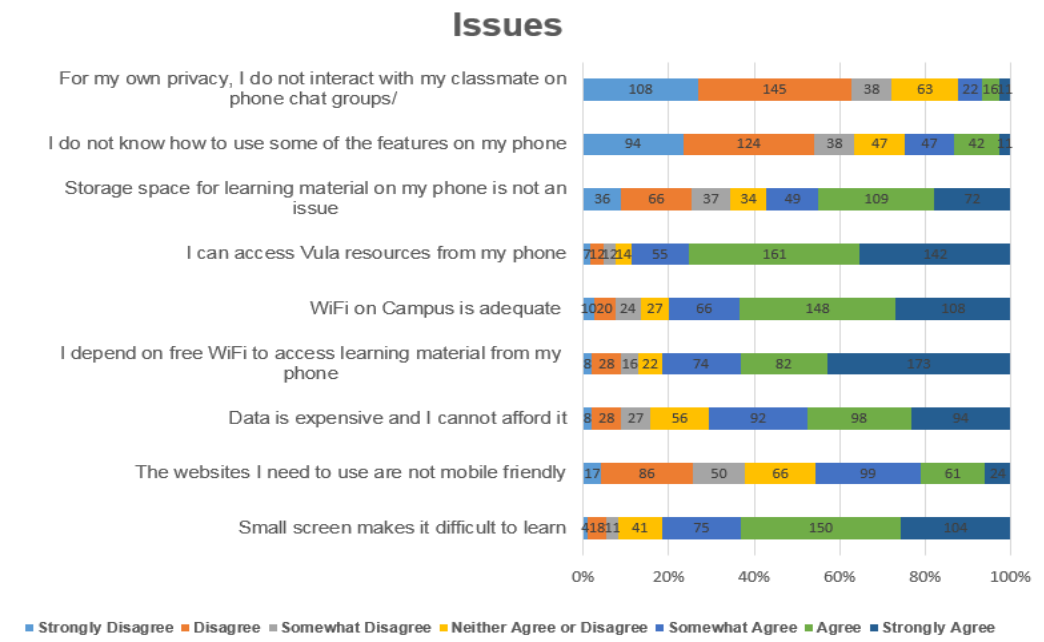

Figure 5: Issues experienced by smartphone users.

\section{Satisfaction}

User satisfaction was found be to generally high for most aspects of learning. The last question under this construct confirmed this as 86, 99 and 39 responded 'somewhat agree', 'agree' and 'strongly agree' respectively. Most students agreed that they can access learning materials from their smartphones, which is of particular importance in enabling mobile learning from a smartphone. Interestingly, although there is quite a difference among the response distributions for the different test items, responses correlated strongly and, consequently, they all loaded on the same 'satisfaction' construct (refer to the validity analysis). 


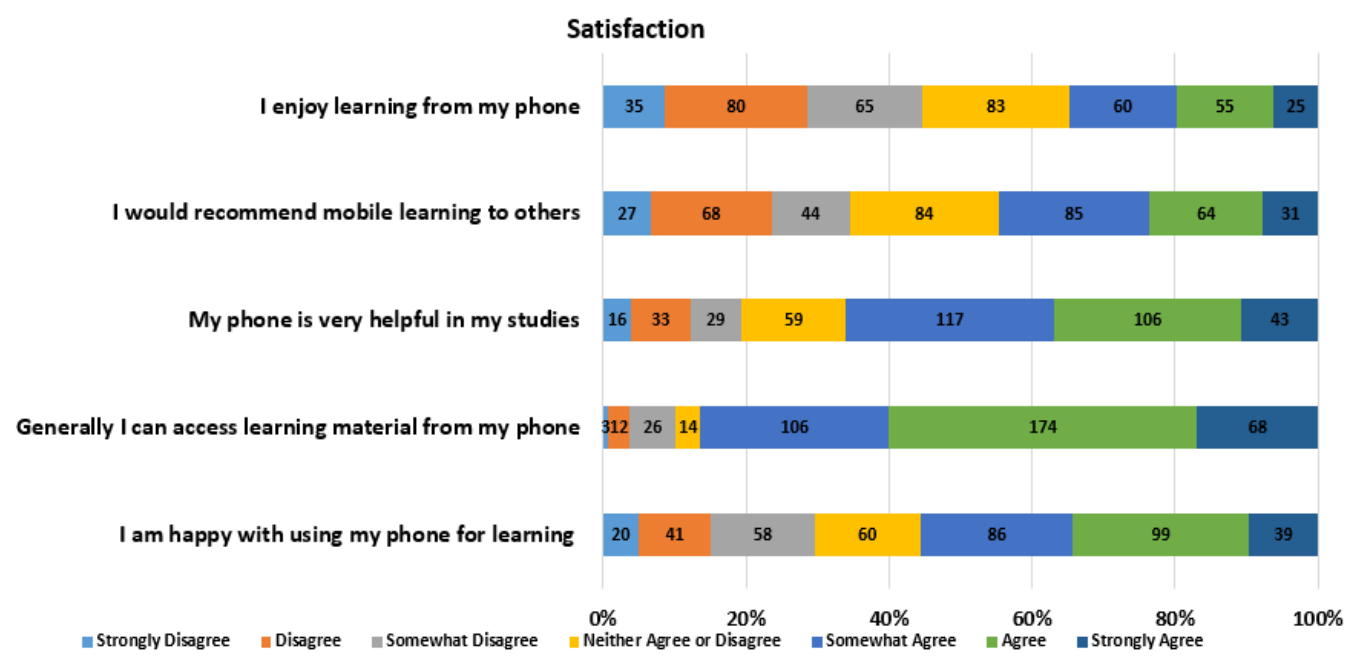

Figure 6: Satisfaction with using a mobile phone for learning purposes.

\subsection{Validity Analysis}

Exploratory Factor analysis was run on all five the constructs, with an Eigen Value cut-off of 0.8 (Verimax Nomalised).

On the frequency of use construct, we had a total of three loadings for the 10 items tested. Firstly, frequency of use of Facebook, Instant Messenger, Camera and Maps loaded under one factor. This is because these applications are all social applications and participants would have viewed them as the same. These application uses were all grouped into one construct called Social. Productivity tool apps such as email, browser, storage and calculator all loaded on the same factor. These were grouped under a new construct called Tools. Memo did not load onto any factor and was consequently removed from the analysis. YouTube loaded on its own factor and a new construct was created called Video.

The questions which referred to the positive impacts of smartphone use on students loaded onto three factors. Time, comfort, productivity and anywhere all speak to one construct which is Location. Ask questions and chat groups loaded onto the same factor and a construct called Support was formed. Enhanced understanding loaded onto its own factor and a third construct was created namely Understanding.

Negative impact had two loadings in total. Distracting in class was loaded onto its own factor called Class. Distraction and Phone was grouped into one construct which was called Distraction. Isolated did not load onto any factor and was removed from the analysis. Storage could not have been viewed as a negative impact but rather an issue as it also appeared under the issues construct and paired with Issue Storage. Therefore, this test item was moved from the negative impacts and included under the issues construct.

The Issues construct had four factors on to which the test items loaded. The following constructs were created based on the factor loadings. Screen size, Mobile unfriendly, Data Connection and Vula (LMS). Campus Wi-Fi loaded separately from the other data connection variables due to the way the question was phrased. This variable was therefore excluded from the analysis.

The Satisfaction construct had all its items loading on the same factor except for one item which loaded together with Vula under issues. Three constructs were created under this cluster i.e. helpful, enjoy and recommend.

All constructs had Cronbach Alpha values above 0.60, most were above 0.80 . 


\subsection{Hypothesis Testing}

Hypotheses $1 \& 2$ : Smartphone use results in both positive and negative impacts.

Several multiple regression tests were performed, each one using the three use cases (use of smartphone tools, social media and for videos) as independent variables with the various negative and positive impacts as respective dependent variables. Table 1 below shows the p-values for each of the 3 identified smartphone use cases (independent variables) per regression (each impact is a separate regression/column). P-values $<0.05$ are highlighted $(*)$.

Table 1: Influence of smartphone use case on learning impacts (p-values/ $\mathbf{R}^{2}$ )

\begin{tabular}{|c|c|c|c|c|c|}
\hline $\begin{array}{l}\text { Regression for } \rightarrow \\
\text { Smartphone use } \downarrow\end{array}$ & $\begin{array}{l}\text { Learn } \\
\text { anywhere } \\
\text { (location) }(+)\end{array}$ & $\begin{array}{l}\text { Better } \\
\text { understandi } \\
\text { ng }(+)\end{array}$ & $\begin{array}{l}\text { Better } \\
\text { support } \\
\text { from others } \\
(+) \\
\end{array}$ & $\begin{array}{l}\text { Distractin } \\
\mathrm{g}(-)\end{array}$ & $\begin{array}{l}\text { Less } \\
\text { concentrati } \\
\text { on in class } \\
(-)\end{array}$ \\
\hline as a tool & $0.0000 *$ & $0.0000 *$ & 0.1006 & $0.0003^{*}$ & $0.0023^{*}$ \\
\hline for social/communication & $0.0017 *$ & 0.4207 & $0.0059 *$ & 0.6680 & 0.7689 \\
\hline for video & 0.1978 & 0.1533 & 0.4331 & $0.0167 *$ & 0.0817 \\
\hline$R^{2}$ & 0.1489 & 0.0822 & 0.0464 & 0.0897 & 0.1175 \\
\hline Adjusted $R^{2}$ & 0.1426 & 0.0752 & 0.0393 & 0.0712 & 0.0995 \\
\hline
\end{tabular}

From the analysis, it is clear that the functional use cases of the smartphone influence the positive or negative impacts differentially. For instance, the various smartphone tools used (calendar, browser, calculator) are significant antecedents on most impacts but the social/communication uses of smartphones (instant messaging, email, facebook) only relate significantly on the 'learn anywhere, anytime' and the 'getting support from others' impacts. The use of the smartphone video functionality only has a significant negative impact (distraction during lectures).

Thus Hypotheses 1 and 2 are supported but only weakly so, given that the actual correlation coefficients (bottom two rows) are very low - only 4 to $14 \%$ of the variance is explained. It must be noted that the lack of explanatory power of the impacts (low adjusted $\mathrm{R}^{2}$ ) remains even when demographic variables are used as additional antecedents.

Hypotheses 3, 4 and 5: Smartphone impacts and issues influence satisfaction of the smartphone as a learning aid.

These hypotheses were tested in one go using a multiple regression with the satisfaction construct as the dependent construct. In addition to the positive and negative impacts, as well as the four identified issues, we also included 5 demographic variables as possible antecedents. Table 2 summarizes the regression.

Table 2: Influence of learning impacts and issues on smartphone learning use satisfaction

\begin{tabular}{|l|c|c|c|c|c|c|}
\hline \multirow{2}{*}{$\mathrm{N}=402$} & \multicolumn{6}{|l|}{$\begin{array}{l}\text { Regression Summary for Dependent Variable: Satisfaction } \\
\mathrm{R}=.79035466 \mathrm{R}^{2}=.62466048\end{array}$} \\
\cline { 2 - 7 } & $\mathrm{b}^{*}$ & $\begin{array}{c}\text { Std.Err. } \\
\text { of } \mathrm{b}^{*}\end{array}$ & $\mathrm{~b}$ & $\begin{array}{c}\text { Std.Err. } \\
\text { of } \mathrm{b}\end{array}$ & $\mathrm{t}(387)$ & $\mathrm{p}$-value \\
\hline Intercept & & & 1.646975 & 0.764373 & 2.15467 & 0.031804 \\
\hline DemGender & -0.076888 & 0.032664 & -0.229182 & 0.097361 & -2.35395 & 0.019074 \\
\hline DemProgram & 0.031952 & 0.033439 & 0.098946 & 0.103550 & 0.95555 & 0.339897 \\
\hline DemYear & -0.041598 & 0.032534 & -0.041094 & 0.032140 & -1.27858 & 0.201813 \\
\hline
\end{tabular}


Impacts and Satisfaction of Using Smartphones for Learning in a University ... B-A. Toperesu et al.

\begin{tabular}{|l|c|c|c|c|c|c|}
\hline DemPhoneType & 0.031801 & 0.033360 & 0.352166 & 0.369426 & 0.95328 & 0.341043 \\
\hline DemScreenSize & 0.000934 & 0.031935 & 0.001899 & 0.064929 & 0.02924 & 0.976686 \\
\hline PosLocation & 0.514129 & 0.047112 & 0.562837 & 0.051576 & 10.91284 & 0.000000 \\
\hline PosSupport & 0.130767 & 0.033464 & 0.145699 & 0.037285 & 3.90768 & 0.000110 \\
\hline PosUnderstanding & 0.001094 & 0.035996 & 0.001240 & 0.040788 & 0.03040 & 0.975763 \\
\hline NegClassUse & -0.032275 & 0.037785 & -0.030643 & 0.035875 & -0.85416 & 0.393542 \\
\hline NegDistraction & -0.238062 & 0.045651 & -0.205070 & 0.039324 & -5.21488 & 0.000000 \\
\hline IssScreenSize & -0.045052 & 0.033079 & -0.047740 & 0.035053 & -1.36196 & 0.174003 \\
\hline IssContentMobile & -0.034786 & 0.033660 & -0.030450 & 0.029465 & -1.03345 & 0.302039 \\
\hline IssDataCost & 0.029178 & 0.032762 & 0.031394 & 0.035250 & 0.89061 & 0.373691 \\
\hline IssVula (LMS) & 0.080364 & 0.032605 & 0.087041 & 0.035313 & 2.46481 & 0.014142 \\
\hline
\end{tabular}

The positive impacts of being able to learn anytime/anywhere (PosLocation) and being able to get support from other students or teachers (PosSupport) positively influence learner satisfaction lending strong but partial support to Hypothesis 3 . The distractive nature of the device has a significant negative effect on learner satisfaction, partially supporting Hypothesis 4. Most issues (screen size, lack of appropriately formatted content, data costs) don't seem to affect satisfaction except that the ability to access the University's Learning Management System using a mobile device adds further satisfaction. Thus Hypothesis 5 must be rejected given that, although students experience certain issues (see figure 5), these issues don't affect satisfaction. Interestingly, satisfaction is also gender-biased with women reporting overall marginally but statistically significantly lower satisfaction levels. The overall power of the model to explain student satisfaction with the smartphone as a learning tool is surprisingly high, with a $\mathrm{R}^{2}$ of 0.625 (adjust $\mathrm{R}^{2}=0.611$ ) i.e. more than $60 \%$ of the variance in student satisfaction is explained by the hypothesized antecedents. However, the model could be made more parsimonious by just selecting the significant variables.

Hypothesis 6: Satisfaction with smartphone influences continued use.

The correlation of satisfaction with smartphone use is significant and above $25 \%$ : use as a tool is highest (0.312), with use for social/communication functions (0.267) and use of video functionality (0.264) also being relatively high. The correlation does not imply causality; however, when the use case factors are included in a multiple regression with the other variables (see previous section), the overall explanatory power $\left(\mathrm{R}^{2}\right.$ value) of the regression equation increases by less than $1 \%\left(\mathrm{R}^{2}=.637\right.$; adjusted $\mathrm{R}^{2}=0.620$ ). Thus, the causal relationship can be assumed to go the other direction i.e. satisfaction leads to (continued) use of those functions that contribute to the learning impacts.

\section{Conclusion}

For the current generation of South African university students, mobile phones are part of their life worlds, and research and practice shows that almost all students currently have smartphones. This research set out to see how these students are using their smartphones as a learning tool in their studies. It was hypothesized that the different smartphone functionalities each have distinct positive and negative impacts on their learning. Furthermore, these impacts, as well as any issues experienced, can be assumed to correlate strongly with the students' satisfaction of using the smartphone as a learning aid.

We found that the uses of smartphones for learning purposes can be grouped into three main functional areas: as a supporting tool (e.g. calculator, browser, calendar), to communicate with fellow students or instructors, and the video/multimedia capability. 
Impacts and Satisfaction of Using Smartphones for Learning in a University ... B-A. Toperesu et al.

The data showed that the positive impacts outweigh the negative impacts substantially. Although the different functional uses of the smartphone are significantly correlated with various positive and negative impacts, the different use cases only explain a tiny fraction (4\% to 14\%) of the variability in impacts, so other antecedents will be needed to explain smartphone impact on learning.

On the other hand, the proposed model of positive and negative impacts, as well as the lack of any serious issues experienced, offer a good (>60\%) explanation of the variability in user satisfaction with using smartphones for learning purposes. Interestingly, female students appear to be slightly less satisfied.

Finally, there is some statistical support for the notion that the satisfaction leads to continued use in a learning context, rather than use impacting on satisfaction directly.

This study was limited to an online survey conducted at a single higher education institution in South Africa. Further research at other universities can assist to validate or extend our findings. In particular, the weak link between use and impact need to be explored further i.e. other drivers for achieving learning impact need to be uncovered. The generalizability of the presumed positive and negative impact classifications would also be useful.

It is hoped that university administrators and academic staff will note the pervasiveness of use and positive impact of the smartphone in student learning. Thus, attention should be given to providing learning materials and other resources in a mobile-friendly format, provision of free and ample bandwidth on- and off-campus, and ensuring that the university’s learning management system has a mobile-friendly dedicated interface.

\section{References}

Abachi, H. R., \& Muhammad, G. (2014). The impact of m-learning technology on students and educators. Computers in human behavior, 30, 491-496. doi:https://doi.org/10.1016/j.chb.2013.06.018

Al-Emran, M., Elsherif, H. M., \& Shaalan, K. (2016). Investigating attitudes towards the use of mobile learning in higher education. Computers in human behavior, 56, 93-102. doi:http://doi.org/10.1016/j.chb.2015.11.033

Ally, M. (2013). Mobile learning: From research to practice to impact education. Learning and Teaching in Higher Education: Gulf Perspectives, 10(2), 1-10.

Ally, M., Grimus, M., \& Ebner, M. (2014). Preparing teachers for a mobile world, to improve access to education. Prospects, 44(1), 43-59. doi:http://doi.org/10.1007/s11125-014-9293-2

Aloul, F. A. (2012). The need for effective information security awareness. Journal of Advances in Information Technology, 3(3), 176-183. doi:doi:10.4304/jait.3.3.176-183

Alrasheedi, M., \& Capretz, L. F. (2013). A meta-analysis of critical success factors affecting mobile learning. Paper presented at the Proceedings of 2013 IEEE International Conference on Teaching, Assessment and Learning for Engineering (TALE).

Bhattacherjee, A. (2001). Understanding information systems continuance: an expectationconfirmation model. MIS quarterly, 351-370. doi:10.2307/3250921

Briz-Ponce, L., Pereira, A., Carvalho, L., Juanes-Méndez, J. A., \& García-Peñalvo, F. J. (2017). Learning with mobile technologies-Students' behavior. Computers in human behavior, 72, 612-620. doi:https://doi.org/10.1016/j.chb.2016.05.027

Brown, T. H., \& Mbati, L. S. (2015). Mobile learning: Moving past the myths and embracing the opportunities. International Review of Research in Open and Distributed Learning, 16(2), 115-135. doi:http://doi.org/10.19173/irrodl.v16i2.2071

Dahlstrom, E., \& Bichsel, J. (2014). ECAR Study of Undergraduate Students and Information Technology, 2014. Educause. 
Impacts and Satisfaction of Using Smartphones for Learning in a University ... B-A. Toperesu et al.

David, L. (2007). "Behaviorism". Learning Theories. Retrieved from http://www.learningtheories.com/behaviorism.html

David, L. (2015). "Constructivism". Learning Theories. Retrieved from http://www.learningtheories.com/constructivism.html

Ellis, R. A., Ginns, P., \& Piggott, L. (2009). E - learning in higher education: some key aspects and their relationship to approaches to study. Higher Education Research \& Development, 28(3), 303-318. doi:https://doi.org/10.1080/07294360902839909

García-Peñalvo, F. J., \& Conde, M. Á. (2015). The impact of a mobile personal learning environment in different educational contexts. Universal Access in the Information Society, 14(3), 375-387. doi:http://doi.org/10.1007/s10209-014-0366-z

Guri-Rosenblit, S. (2005). 'Distance education'and 'e-learning’: Not the same thing. Higher education, 49(4), 467-493. doi:https://doi.org/10.1007/s10734-004-0040-0

Haley, K. (2015). 2015 Internet Security Threat Report: Attackers are bigger, bolder, and faster. Retrieved from https://www.symantec.com/connect/blogs/2015-internet-security-threatreport-attackers-are-bigger-bolder-and-faster

Hashemi, M., Azizinezhad, M., Najafi, V., \& Nesari, A. J. (2011). What is mobile learning? Challenges and capabilities. Procedia-Social and Behavioral Sciences, 30, 2477-2481. doi:https://doi.org/10.1016/j.sbspro.2011.10.483

Kaliisa, R., \& Picard, M. (2017). A Systematic Review on Mobile Learning in Higher Education: The African Perspective. Turkish Online Journal of Educational Technology-TOJET, 16(1), 1-18. doi:http://doi.org/10.1017/CBO9781107415324.004

Kobus, M. B., Rietveld, P., \& Van Ommeren, J. N. (2013). Ownership versus on-campus use of mobile IT devices by university students. Computers \& Education, 68, 29-41. doi:https://doi.org/10.1016/j.compedu.2013.04.003

Kuznekoff, J. H., \& Titsworth, S. (2013). The impact of mobile phone usage on student learning. $\begin{array}{lll}\text { Communication 233-252. } & \text { 62(3), }\end{array}$ doi:http://doi.org/10.1080/03634523.2013.767917

Lau, K. P., Chiu, D. K., Ho, K. K., Lo, P., \& See-To, E. W. (2017). Educational usage of mobile devices: Differences between postgraduate and undergraduate students. The Journal of Academic Librarianship, 43(3), 201-208. doi:http://doi.org/10.1016/j.acalib.2017.03.004

Magunje, C. G. (2013). Using mobile phones to support learning: a case of UCT first year female science students in the Academic Development Programme. University of Cape Town, South Africa.

Moreira, F., Pereira, C. S., Durão, N., \& Ferreira, M. J. (2018). A comparative study about mobile learning in Iberian Peninsula Universities: Are professors ready? Telematics and Informatics, 35(4), 979-992. doi:http://doi.org/10.1016/j.tele.2017.09.010

Ossiannilsson, E. (2016). Quality enhancement for mobile learning in higher education. In HumanComputer Interaction: Concepts, Methodologies, Tools, and Applications (pp. 2092-2107): IGI Global.

Ozdamli, F., \& Cavus, N. (2011). Basic elements and characteristics of mobile learning. ProcediaSocial and Behavioral Sciences, 28, 937-942. doi:https://doi.org/10.1016/j.sbspro.2011.11.173

Pozár, J. (2014). Modelling of the Investigation of Cybercrime. Science \& Military Journal, 9(1), 63.

Rouse, M. (2011). Endpoint Security. Retrieved from http://searchmidmarketsecurity.techtarget.com/definition/endpoint-security

Santos, I. M. (2015). Mobile devices in higher education classrooms: Challenges and opportunities. In Promoting active learning through the integration of mobile and ubiquitous technologies (pp. 37-54): IGI Global.

Saunders, M., Lewis, P., \& Thornhill, A. (2009). Research methods for business students: Pearson Education Limited. 
Siemens, G. (2005). Connectivism: A Learning Theory for the Digital Age. Int. J. Instr. Technol. Distance Learn, 2(1), 1-9.

Sincero, S. M. (2011). Cognitive Learning Theory. Retrieved from https://explorable.com/cognitivelearning-theory

Vishwakarma, A. (2015). Benefits and challenges of mobile learning in education. In Promoting active learning through the integration of mobile and ubiquitous technologies (pp. 24-36): IGI Global.

Wai, I. S. H., Ng, S. S. Y., Chiu, D. K., Ho, K. K., \& Lo, P. (2018). Exploring undergraduate students' usage pattern of mobile apps for education. Journal of Librarianship and Information Science, 50(1), 34-47. doi:http://doi.org/10.1177/0961000616662699

Wu, W.-H., Wu, Y.-C. J., Chen, C.-Y., Kao, H.-Y., Lin, C.-H., \& Huang, S.-H. (2012). Review of trends from mobile learning studies: A meta-analysis. Computers \& Education, 59(2), 817-827. doi:https://doi.org/10.1016/j.compedu.2012.03.016

Yusuf, O. M., Lawal, B. I., \& Oyewusi, M. B. (2015). Effectiveness of Using Mobile Technologies in Teaching and Learning. In Promoting Active Learning through the Integration of Mobile and Ubiquitous Technologies (pp. 155-166): IGI Global.

Zolkipli, M. F., \& Jantan, A. (2010). A framework for malware detection using combination technique and signature generation. Paper presented at the 2010 Second International Conference on Computer Research and Development. 